\title{
Cooking methods affect total fatty acid composition and retention of DHA and EPA in selected fish fillets
}

\author{
Poh Yee Choo ${ }^{a}$, Azrina Azlan ${ }^{a, b, c, *}$, Hock Eng Khoo ${ }^{a, c}$ \\ a Department of Nutrition and Dietetics, Faculty of Medicine and Health Sciences, \\ Universiti Putra Malaysia, 43400 UPM Serdang, Selangor, Malaysia \\ b Laboratory of Halal Science Research, Halal Products Research Institute, Universiti Putra Malaysia, \\ 43400 UPM Serdang, Selangor, Malaysia \\ c Research Centre of Excellence for Nutrition and Non-Communicable Disease, \\ Faculty of Medicine and Health Sciences, Universiti Putra Malaysia, 43400 UPM Serdang, Selangor, \\ Malaysia \\ *Corresponding author, e-mail: azrinaaz@upm.edu.my
}

Received 5 Jun 2017

Accepted 23 Jan 2018

\begin{abstract}
Changes in total fatty acids in fillets of yellowstripe scad, Japanese threadfin bream, and salmon when applying different cooking methods were evaluated. All fish fillets (100 $\mathrm{g}$ fresh weight) were subjected to deep drying, grilling, baking in foil, and steaming. The results showed that deep frying of Japanese threadfin bream fillet significantly increased the total saturated fatty acid $(955 \mathrm{mg} / 100 \mathrm{~g}$ ) compared with the other cooking methods (499-612 mg/100 g). Baking in foil showed a significantly lower retention of total monounsaturated fatty acid in all fish fillets compared to the raw sample, especially yellowstripe scad with a total monounsaturated fatty acid content of $175 \mathrm{mg} / 100 \mathrm{~g}$. Retention of DHA + EPA (mg/100 g) in yellowstripe scad fillet was found to be the highest by applying steaming method (112) compared to the raw fillet (119), followed by baking in foil (108), grilling (99), and deep frying (93). Steaming and baking in foil methods were able to retain the DHA and EPA content in the cooked fillets of all types of the studied fish compared to raw fillet. Deep frying and grilling methods showed a significant reduction of DHA and EPA contents in all fish fillets compared with steaming and baking in foil. The effect of different cooking methods was found to be significantly associated with the true retention values of DHA and EPA. In conclusion, steaming and baking in foil would be the best cooking methods for retention of DHA and EPA in yellowstripe scad fillet.
\end{abstract}

KEYWORDS: docosahexaenoic acid, eicosapentaenoic acid, Nemipterus japonicus, salmon, Selaroides leptolepis

\section{INTRODUCTION}

Aquatic ecosystems are the main contributors of DHA (docosahexaenoic acid, 22:6n-3) and EPA (eicosapentaenoic acid, 20:5n-3) in human diet, thus humans obtain these polyunsaturated fatty acids (PUFAs) through consumption of fish and other marine and freshwater products. The rate of consumption of marine fish, other marine products, and freshwater products among Malaysian population is very high, which accounted for $93 \%$, $93 \%$, and $95 \%$, respectively ${ }^{1}$. The high rate of fish consumption in Malaysia shows that the majority of Malaysians have knowledge of nutritional content of fish, especially PUFA.

Raw fish fillet is cooked using different ways before consumption. Thermo-sensitive compounds such as fat-soluble vitamins and PUFAs in fish fillets can be affected by cooking. Composition of PUFA also varies among fish species. Due to the high content of long-chain PUFAs in fish, these marine lipids are highly susceptible to oxidation ${ }^{2}$. In fact, higher degree of unsaturation in PUFAs tends to have lower melting points ${ }^{3}$, which indicates that, when the temperature increases, PUFA content decreases because high temperature causes a crossover in temperature threshold which leads to degradation of PUFA in fish samples ${ }^{4}$.

Several studies have been performed to examine the effects of different cooking methods on fatty acids content in fish species. The effect of different cooking methods (frying, steaming, oven cooking, and microwave cooking) on fatty acid profiles of red mullet fillets was determined in Ref. 3, where DHA and EPA content did not differ much in the fish samples. Similar findings are also reported in Ref. 5. In contrast, some negative findings revealed that long-chain PUFAs are susceptible to oxidation 
during heating and other culinary treatments ${ }^{6}$.

From a nutritional point of view, it is necessary to recommend the best cooking method for retaining nutritional and healthy attributes of fish fillets, especially PUFA. Our previous study also found that fillets of yellowstripe scad and Japanese threadfin bream had the highest DHA and EPA content among the studied fish samples ${ }^{7}$. This study is, therefore, conducted to determine the effect of different cooking methods on the retention of total fatty acids, DHA, and EPA, as well as its retention values of fillets of yellowstripe scad and Japanese threadfin bream, the common local marine fish that is caught from the Straits of Malacca and commonly consumed by Southeast Asian populations. Comparison was made between fillets of the selected fish and salmon because salmon has been known for its rich source of DHA and $\mathrm{EPA}^{8}$.

\section{MATERIALS AND METHODS}

\section{Chemicals and reagents}

Analytical and chromatography grade of chemicals and reagents were used in this study. Methanol, chloroform, and isooctane were purchased from Merck kGaA (Darmstadt, Germany). Butylated hydroxytoluene (BHT), $\mathrm{NaOH}$, boron trifluoride $\left(\mathrm{BF}_{3}\right)$, and $\mathrm{NaCl}$ were purchased from Sigma-Aldrich (M) Sdn Bhd (Selangor, Malaysia). The 37-component FAME mix standard $47885-\mathrm{U}$ (Supelco, Germany) was used as an external standard for fatty acid analysis.

\section{Sample preparation}

A total of $5.0 \pm 1.0 \mathrm{~kg}$ of each yellowstripe scad (Selaroides leptolepis) and Japanese threadfin bream (Nemipterus japonicus) was obtained from the wet market in Serdang, Selangor, Malaysia, whereas $5.0 \pm 0.5 \mathrm{~kg}$ of farmed salmon fillet (Salmo salar) was purchased from a local supermarket nearby Universiti Putra Malaysia. A mixture of small to medium sizes of yellowstripe scad and Japanese threadfin bream (100-150 g per fish) was selected randomly from the bin. All samples were placed in an icebox filled with ice packs after purchase and instantly transferred to the laboratory. The average length of the salmon was $35 \mathrm{~cm}$, and $15-20 \mathrm{~cm}$ for the local fish. Freshness of the fish (bright hue of fish skin, translucent corners of the eyes, firm flesh, fresh aroma, and stiffness of fish muscle) was taken into consideration during purchasing the sample.

Before cooking, the fish were eviscerated and two portions of fillet were obtained after the head has been removed. Briefly, an exact $100.0 \mathrm{~g}$ of each fish sample (the fillet from 2-3 fishes) was obtained. The fish sample was seasoned with salt for $10 \mathrm{~min}$ prior to cooking. Later, the seasoned fish samples were cooked with dry-heat cooking methods (frying and grilling) and moist-heat cooking methods (steaming and baking in foil) with three replicates. For raw fish samples, the fish fillets were stored in a freezer $\left(-20^{\circ} \mathrm{C}\right)$ until the extraction of fat was performed.

\section{Frying}

Frying protocol was adopted from a conventional frying method. A frying pan with two-litre capacity was used. Briefly, $500 \mathrm{ml}$ of palm oil (commercial type) was poured into the frying pan and heated for 5 min until the oil started to boil. A digital thermocouple was used to measure the surface temperature until it reached $180^{\circ} \mathrm{C}$. Then the seasoned fish samples were immersed in the heated oil and deep-fried for $8 \mathrm{~min}$. During the $8 \mathrm{~min}$ deep frying, the samples were turned over and deep-fried at 2min interval. The samples were intact during the 8min deep frying. After the cooking, a dry absorbent No. 1 Whatman filter paper was placed under the cooked samples to absorb excessive oil.

\section{Grilling}

Grilling protocol was established in our laboratory. Stainless steel grill was used and grilling of the seasoned fish samples was done in an electrically operated Convotherm oven at $180^{\circ} \mathrm{C}$. The samples were placed inside the oven for grilling. The seasoned samples was grilled for 10 min, turned over, and grilled for another $10 \mathrm{~min}$. The grill was slightly greased before cooking, with a spread of $10 \mathrm{ml}$ of palm oil in order to avoid the fillet from sticking to the base.

\section{Steaming}

Steaming protocol was adopted from Ref. 3. Briefly, a stainless steel 5-quart steamer was filled with 2.51 of filtered water. The filtered water was brought to boil and the seasoned fish samples were placed into the steamer basket over water. The steamer was covered with a lid and the fish samples were steamed for $10 \mathrm{~min}$. The steamer was kept at high fire throughout the cooking.

\section{Baking in foil}

Baking protocol was adopted from Ref. 9. Briefly, each seasoned fish sample was wrapped with $10 \times 10$ in of aluminium foil and baked using a 
preheated electrically operated Convotherm oven set at $180^{\circ} \mathrm{C}$, up to a final internal temperature of $75^{\circ} \mathrm{C}$ as measured using a digital thermocouple for $30 \mathrm{~min}$. After $30 \mathrm{~min}$, the foil wrapped samples were taken out from the oven and the foil was cut with scissors to obtain the baked fish fillet.

\section{Cooking yield}

Weight of the fish samples for each type of cooking method was recorded before and after cooking to determine the cooking yield, which was expressed as a percentage.

\section{Extraction of fat}

Extraction of fat was conducted based on the method reported in Ref. 10 with slight modifications. A representative fish sample (30 g of fillet) was homogenized for 2 min using a Waring laboratory blender with a mixture of methanol $(60 \mathrm{ml})$ and chloroform $(30 \mathrm{ml})$. One volume of chloroform $(30 \mathrm{ml})$ was added to the mixture and was blended for another $30 \mathrm{~s}$. After blending, $30 \mathrm{ml}$ of distilled water was added to the mixture. A glass rod was used to stir the homogenate and Whatman No. 1 filter paper was used to filter the homogenate on a Buchner funnel with slight suction. After filtration, the filtrate was transferred to a separating funnel to separate aqueous and organic phases. Lower clear phase (organic phase-chloroform) was drained into a $250 \mathrm{ml}$ round-bottom flask. Then it was concentrated in a rotary evaporator at $40^{\circ} \mathrm{C}$ to remove excessive chloroform.

\section{Preparation of fatty acid methyl esters}

Preparation of fatty acid methyl esters (FAME) was done according to the method reported in Ref. 11. Briefly, $25 \mathrm{mg}$ of the extracted fish oil, unheated, and heated palm oil samples were weighed and added to $1.5 \mathrm{ml}$ of $0.50 \mathrm{M} \mathrm{NaOH}$ in methanol in a $15 \mathrm{ml}$ capped centrifuge tube. The mixture was then heated in a water bath at $100^{\circ} \mathrm{C}$ for $5 \mathrm{~min}$ and cooled to room temperature. After cooling, $2.0 \mathrm{ml}$ of $12 \% \mathrm{BF}_{3}$ in methanol was added to the mixture and the mixture was once again heated in a water bath at $100^{\circ} \mathrm{C}$ for $30 \mathrm{~min}$. Immediately, after this step, $1 \mathrm{ml}$ of isooctane was added to the tube followed by vigorously stirring for $30 \mathrm{~s}$. Finally, $5 \mathrm{ml}$ of saturated $\mathrm{NaCl}$ solution was added to facilitate phase separation.

\section{Gas chromatography analysis}

Analysis of FAME was performed by a capillary gas chromatography from Agilent Technologies, model
Agilent 6890 (CA, USA), equipped with a splitsplitless injector and a flame ionization detection system. A highly polar HP88 column from Agilent Technologies $(100 \mathrm{~mm} \times 0.25 \mathrm{~mm} \times 0.2 \mu \mathrm{m}$ ID) was used to separate and quantify the FAME. Helium was used as the carrier gas in this system at a linear velocity of $30.0 \mathrm{ml} / \mathrm{min}$. Split injection with a split ratio (volume of gas passing to waste:volume of gas passing down the capillary column) of 10:1 and $10.0 \mathrm{ml} / \mathrm{min}$ of split flow were applied. The operation conditions were set to be $250^{\circ} \mathrm{C}$ injection port, $250^{\circ} \mathrm{C}$ flame ionization detector and $200^{\circ} \mathrm{C}$ column temperature. After the analysis, all compounds were identified by comparing with the retention time of 37 components FAME mix $47885-\mathrm{U}$ (Supelco, Germany).

\section{Quantification of total fatty acids, DHA, and EPA in fish samples}

Quantification of total fatty acids, DHA, and EPA was done based on two ways. For raw fish samples, the amounts of fatty acids were calculated based on both area normalization method and standard calibration curve method. The cooked fish samples were only determined using the standard calibration curve method.

Area normalization method was used during identifying every single fatty acid in the samples. Based on previous literature ${ }^{12}$, the fraction of fatty acids was calculated as total fatty acids, DHA, and EPA based on the peak area of the fatty acid in relation to the total peak area of all eluted fatty acids in raw fish samples: fraction of total fatty acids $=$ $A / B$, where $A$ is the area of a specific fatty acid and $B$ is the area of total fatty acids present.

For standard calibration method, calibration linear equation was obtained from plotted graph of each 37 components FAME mix 47885 -U standard (Supelco, Germany), with dilution factor of $10 \times$, $20 \times, 30 \times, 40 \times$, and $50 \times$. Total fatty acids, DHA, and EPA of raw fish samples were quantified based on equation of the calibration curves. The fatty acids content in both raw and cooked fish samples was presented as $\mathrm{mg}$ per $100 \mathrm{~g}$ fresh weight (FW).

\section{Quantification of fatty acid composition of unheated and heated frying oil}

Determination and quantification of fatty acids in the unheated and heated frying oil (palm oil) were performed for the purpose of ensuring the oil used could affect the type and amount of fatty acids determined in the fish samples. Fatty acid composition 
of the frying oil samples was determined based on the standard calibration method

\section{True retention values of DHA and EPA}

Fatty acids content through quantitative analysis, combined with cooking yields, was used to calculate true retention value (TRV) of DHA and EPA in the selected fish samples upon using different cooking methods (steaming, frying, grilling, and baking in foil), based on the formula reported in Ref. 13 as:

$$
\mathrm{TRV}=\frac{\mathrm{NC}_{\text {cooked }} \mathrm{FW}_{\text {cooked }}}{\mathrm{NC}_{\text {raw }} \mathrm{FW}_{\text {raw }}}
$$

where $\mathrm{NC}_{\text {cooked }}=$ nutrient content per g of cooked food, $\mathrm{NC}_{\text {raw }}=$ nutrient content per $\mathrm{g}$ of raw food, $\mathrm{FW}_{\text {cooked }}=\mathrm{g}$ of food after cooking, and $\mathrm{FW}_{\text {raw }}=\mathrm{g}$ of food before cooking.

\section{Statistical analysis}

Statistical analysis was performed using IBM SPSS Statistics 22.0 and expressed as mean \pm SD. Paired sample $t$-test was applied to determine mean differences of DHA and EPA content before and after cooking. One-way ANOVA coupled with GamesHowell post-hoc test was used to compare statistical significance of mean concentrations of DHA and EPA of the selected fish samples among different cooking methods at $p<0.05$. Games-Howell post-hoc test was considered because the data did not meet the homogeneity of variances. Chi-squared test was also used to determine association between the effect of different cooking methods and retention of DHA and EPA in the fish samples.

\section{RESULTS AND DISCUSSION}

\section{Moisture and fat content of raw fish fillets}

Based on the results obtained, raw fillet of Japanese threadfin bream had the highest moisture content $(82.0 \pm 0.2 \%)$, followed by raw fillets of yellowstripe scad $(77.5 \pm 0.2 \%)$ and salmon $(71.6 \pm 0.5 \%)$. Total fat content in the raw fish fillet was the highest in salmon $(9.45 \pm 0.05 \%)$ compared with raw fillets of yellowstripe scad $(1.84 \pm 0.08 \%)$ and Japanese threadfin bream $(1.28 \pm 0.14 \%)$. A previous study reported a higher moisture content of $80 \pm 3 \%$ and $79 \pm 1 \%$ for raw fillets of yellowstripe scad and Japanese threadfin bream, respectively, compared to the moisture content determined in this study ${ }^{14}$. Fat content in raw fillets of yellowstripe scad and Japanese threadfin bream determined in this study ( $2.7 \pm 0.4 \%$ and $2.1 \pm 0.5 \%$, respectively) was lower than the fat content that reported in the

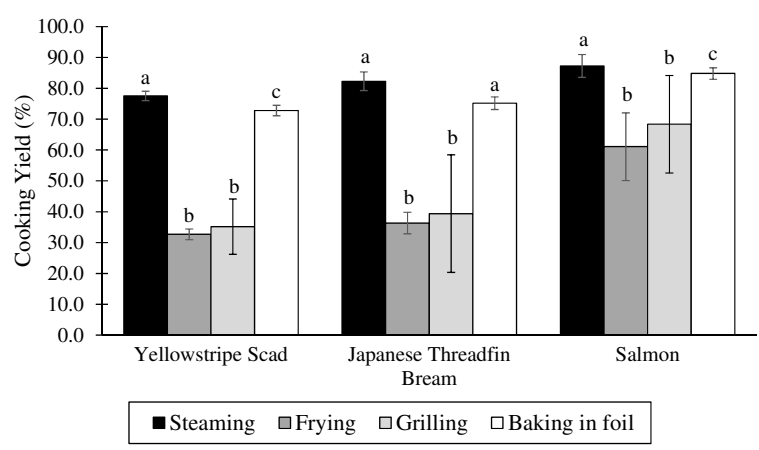

Fig. 1 Cooking yield of fish fillets applying different cooking methods. Data are expressed as mean \pm SD (\%) of triplicate analyses. Bars with different lowercase letters $(a-c)$ indicate significant difference between different cooking methods for same fish sample at $p<0.05$ (Games-Howell post-hoc test).

literature ${ }^{7}$. The variation of fat content in these raw fish samples could be due to different trophic levels and food sources.

\section{Cooking yield}

Cooking yield from all cooking methods was obtained by weighing the fish fillets before and after cooking. Fig. 1 shows cooking yield of yellowstripe scad, Japanese threadfin bream, and salmon using different cooking methods (steaming, frying, grilling, and baking in foil).

A loss in weight of the cooked fish fillets is probably due to water loss ${ }^{15,16}$, lipid oxidation, and degradation ${ }^{17}$ during cooking. In fact, about $80 \%$ of fish muscle is composed of lipid and water $^{18}$. Heating causes a change in the structure of myofibrillar proteins and the membrane structures and hence lead to water reduction ${ }^{19}$. On the other hand, lipids in foods subjected to high temperatures are susceptible to oxidation ${ }^{20}$. The susceptibility of cooked meat to lipid oxidation is closely related to its lipid content, concentration of unsaturated fatty acids, and the presence of iron in different species ${ }^{21}$. The fact is also supported by the literature which reported that a loss in lipids was noticed after cooking of fatty fish fillets ${ }^{22}$.

In this study, steaming of the fish fillets gave the highest cooking yield, followed by baking in foil, grilling, and frying (Fig. 1). The result obtained from one-way ANOVA showed that cooking yields from both steaming and baking in foil were significantly higher than that of frying and grilling at $p<0.05$. It could be due to the high temperature used in frying $\left(180^{\circ} \mathrm{C}\right)$ and grilling $\left(180^{\circ} \mathrm{C}\right)$ 
Table 1 Fatty acid (\% by wt) composition of palm oil for before and after frying.

\begin{tabular}{lcc}
\hline Fatty acids & Unheated & After frying \\
\hline $12: 0$ & $0.38 \pm 0.05$ & $0.4 \pm 2.3$ \\
$14: 0$ & $1.1 \pm 1.4$ & $1.5 \pm 6.9$ \\
$16: 0$ & $36.3 \pm 9.2$ & $36 \pm 10$ \\
$16: 1$ & $0.2 \pm 1.3$ & $0.1 \pm 1.3$ \\
$18: 0$ & $3.8 \pm 2.0$ & $3.7 \pm 1.0$ \\
$18: 1$ & $44.9 \pm 4.6$ & $46.1 \pm 4.8$ \\
$18: 2$ & $12.5 \pm 2.4$ & $11.1 \pm 2.0$ \\
$18: 3$ & $0.55 \pm 0.19$ & $0.53 \pm 0.14$ \\
$20: 0$ & $0.15 \pm 0.01$ & $0.2 \pm 1.7$ \\
SFA & $41.8 \pm 5.0$ & $42.1 \pm 5.0$ \\
MUFA & $45.1 \pm 3.3$ & $47.4 \pm 3.2$ \\
PUFA & $13.1 \pm 1.9$ & $11.6 \pm 1.8$ \\
\hline
\end{tabular}

Data are expressed as $\%$ of fatty acids (mean \pm SD). In this Table and the following: SFA = saturated fatty acid; MUFA = monounsaturated fatty acid; PUFA = polyunsaturated fatty acid.

compared to steaming $\left(100^{\circ} \mathrm{C}\right)$. Increasing loss in food weight was found for longer heating time and increasing temperature of cooking ${ }^{19}$. On the contrary, baking in foil method showed a higher cooking yield although the baking temperature $\left(180^{\circ} \mathrm{C}\right)$ is the same as for frying and grilling methods. Use of aluminium foil to wrap fish sample might have prevented a drastic increase in internal temperature and internal temperature of the wrapped fish fillet was about $75^{\circ} \mathrm{C}$. This cooking technique is similar to steaming of food where the fish fillet was cooked by its internal steam.

The result also demonstrates that cooking yield of frying and grilling the fillet of salmon was higher than the yield of steamed and baked fillets of the fish. Findings from a previous study showed cooking losses vary greatly with fish species and cooking method $^{23}$. This observation is also supported by another study that there was a statistically significant difference in cooking yield between different fish species ${ }^{24}$. Hence changes in cooking yield between frying and grilling of fillets of the fish could be due to certain factors such as different temperatures and cooking time ${ }^{25}$.

\section{FATTY ACID COMPOSITION OF UNHEATED AND HEATED FRYING OIL}

As shown in Table 1, fatty acid composition of the frying did not significantly change after $8 \mathrm{~min}$ of deep drying of fish samples. The fatty acid composition of the palm oil determined was within the range reported previously ${ }^{26}$.
Table 2 Estimation of DHA and EPA content of raw fish fillet of selected fish.

\begin{tabular}{|c|c|c|c|}
\hline Fatty acids & YS & JTB & Salmon \\
\hline DHA & $3.27 \pm 0.04^{\mathrm{a}}$ & $0.91 \pm 0.02^{\mathrm{b}}$ & $0.48 \pm 0.01^{c}$ \\
\hline EPA & $4.79 \pm 0.56^{\mathrm{ab}}$ & $0.95 \pm 0.05^{\mathrm{a}}$ & $2.07 \pm 0.01^{\mathrm{b}}$ \\
\hline DHA + EPA & $8.06 \pm 0.37^{\mathrm{a}}$ & $1.87 \pm 0.05^{\mathrm{b}}$ & $2.55 \pm 0.01^{c}$ \\
\hline Total SFA & $55.45 \pm 0.21^{\mathrm{a}}$ & $67.59 \pm 0.51^{\mathrm{b}}$ & $30.55 \pm 0.17^{c}$ \\
\hline Total MUFA & $25.19 \pm 0.31^{\mathrm{a}}$ & $23.59 \pm 0.40^{\mathrm{a}}$ & $38.46 \pm 0.19^{b}$ \\
\hline Total PUFA & $19.36 \pm 0.52^{\mathrm{a}}$ & $8.82 \pm 0.11^{\mathrm{a}}$ & $30.99 \pm 0.37^{c}$ \\
\hline \multicolumn{4}{|c|}{$\begin{array}{l}\text { Data are expressed as mean } \pm S D(\%) \text { of triplicate } \\
\text { analyses. Different superscript lowercase letters (a- } \\
\text { c) in the same row indicate significant difference at } \\
p<0.05 \text { (Games-Howell post-hoc test). } \\
\text { In this Table and the following: DHA = docosa- } \\
\text { hexaenoic acid; EPA = eicosapentaenoic acid; YS = } \\
\text { Yellowstripe scad; JTB = Japanese threadfin bream. }\end{array}$} \\
\hline
\end{tabular}

The results also showed that total PUFA was not significantly decreased after deep frying. Although PUFA is not a heat stable fatty acid, the high level of SFA in the frying oil increases oxidative stability of PUFA ${ }^{27}$. Besides the oxidative stability, total SFA in the frying oil increased after deep frying of fish sample. It could be due to the increasing degree of saturation of the double bonds between the carbons of PUFA. Hence a decrease in total PUFA was observed for the heated oil sample (Table 1).

\section{DHA, EPA, and total fatty acids content of raw fish fillets}

As shown in Table 2, DHA, EPA, and total fatty acids content in raw fish fillets was estimated based on the area normalization method and expressed as a percentage of total fatty acids. Also, DHA, EPA, and total fatty acids content of raw fish fillets were quantitatively determined based on standard calibration method (Table 3). Results of both area normalization and standard calibration methods show that raw fish fillet of yellowstripe scad had the highest DHA content, followed by raw fish fillets of salmon and Japanese threadfin bream (Tables 2 and 3). Similarly, EPA content was the highest in raw fish fillet of yellowstripe scad, followed by raw fish fillets of salmon and Japanese threadfin bream. As for DHA = EPA content, both area normalization and standard calibration methods showed that raw fillet of yellowstripe scad had the highest DHA + EPA content, followed by raw fillets salmon and Japanese threadfin bream.

For determination of total fatty acids content in the raw fish fillets based on standard calibration method (Table 3), the result shows that raw fillet of 
Table 3 Quantification of total fatty acids, DHA, and EPA content of raw fish fillet of selected fish.

\begin{tabular}{lccc}
\hline Fatty acids & YS & JTB & Salmon \\
\hline DHA & $50.75 \pm 0.70^{\mathrm{a}}$ & $12.99 \pm 0.03^{\mathrm{b}}$ & $13.48 \pm 0.13^{\mathrm{b}}$ \\
EPA & $68.3 \pm 8.0^{\mathrm{ab}}$ & $12.19 \pm 0.47^{\mathrm{a}}$ & $54.35 \pm 0.04^{\mathrm{b}}$ \\
DHA + EPA & $119.0 \pm 5.1^{\mathrm{a}}$ & $25.18 \pm 0.31^{\mathrm{b}}$ & $67.83 \pm 0.06^{\mathrm{C}}$ \\
Total SFA & $494.4 \pm 2.4^{\mathrm{A}}$ & $561 \pm 23^{\mathrm{A}}$ & $497.0 \pm 4.0^{\mathrm{A}}$ \\
Total MUFA & $212.8 \pm 3.0^{\mathrm{A}}$ & $190.54 \pm 0.39^{\mathrm{A}}$ & $624.2 \pm 3.4^{\mathrm{B}}$ \\
Total PUFA & $273.5 \pm 6.5^{\mathrm{A}}$ & $96.8 \pm 1.2^{\mathrm{B}}$ & $623.9 \pm 9.6^{\mathrm{C}}$ \\
\hline
\end{tabular}

Data are expressed as mean \pm SD (mg/100 g FW) of triplicate analyses. Different superscript lowercase or uppercase letters ( $\mathrm{a}-\mathrm{c}$ and $\mathrm{A}-\mathrm{C}$ ) in the same row indicate significant difference at $p<0.05$ (GamesHowell post-hoc test).

Japanese threadfin bream had the highest total SFA, followed by raw fillets of salmon and yellowstripe scad. However, the total SFA was not significantly different between these raw fish fillets. On the other hand, raw fish fillet of salmon had the significant highest total MUFA and total PUFA compared with raw fillets of yellowstripe scad and Japanese threadfin bream. Total MUFA content in raw fillets of these two local fish was not significantly different. However, total PUFA content in raw fillet of Japanese threadfin bream was almost three times lower than the total PUFA content in raw fillet of yellowstripe scad.

Variation in fatty acids content of raw fish samples could be due to the influence of geographical regions, age, maturity, or other biological factors on fatty acids content in the fish ${ }^{28}$. Other factors such as climate, temperature, rainfall, and water could also influence fatty acids content of fish ${ }^{29}$. Besides, dietary fatty acids pattern and availability of fatty acids in aquatic food chain play important roles for accumulation of fat in subcutaneous layer of fish ${ }^{30}$. Typically, a significant amount of fat is stored in the subcutaneous tissue of fatty fish. Removal of fish skin may eliminate a considerably high amount of fat ${ }^{31}$. Thus in this study, removal of fish skin could have affected total fatty acids, DHA, and EPA contents in the raw fish fillets.

\section{Retention of total fatty acids, DHA, and EPA in cooked fish fillets}

As shown in Table 4, all fried fish fillets had significantly higher total fatty acids content, except for total PUFA. Total PUFA content in the fried fillets was significantly lower compared with the other cooking methods. Total SFA, total MUFA, and total PUFA content in most of the fish fillets prepared by steaming and baking in foil methods were not significantly lower than frying and grilling methods. Besides, these fish fillets cooked with steaming and baking in foil methods had a significantly higher total PUFA content than frying and grilling methods, except for grilled fillet of Japanese threadfin bream. Hence we conclude that frying of fish fillets retained a higher level of total SFA and total MUFA. One of the possible explanations for high total SFA determined in the fried fish fillets is that these fish fillets were deep-fried with high-SFA palm oil, where saturated fat from palm oil was retained in the fried fish fillets after the deep fat frying.

In this study, retention of total PUFA in all cooked fish fillets was significantly lower than raw fish fillets at $p<0.05$ (Table 4). Retention of total SFA and total MUFA in fried and grilled fish fillets was significantly higher than the raw samples at $p<0.05$, except for retention of total SFA and total MUFA in grilled fillets of yellowstripe scad and salmon. Besides, retention of total SFA and total MUFA in steamed and baked fillets of Japanese threadfin bream was not significantly lower than the raw samples $(p \geqslant 0.05)$. Based on these findings, we conclude that the moist-heat cooking (steaming and baking in foil) of Japanese threadfin bream fillet is able to retain most of the total SFA and total MUFA content but not for total PUFA.

Table 4 Total fatty acids content in fish fillets of selected fish prepared using different cooking methods.

\begin{tabular}{llccc}
\hline Sample & Meth. $^{\dagger}$ & Total SFA & Total MUFA & Total PUFA \\
\hline YS & I & $471 \pm 12^{\mathrm{a}^{*}}$ & $188.7 \pm 0.3^{\mathrm{a}^{*}}$ & $253.2 \pm 0.1^{\mathrm{a}^{*}}$ \\
& II & $612 \pm 15^{\mathrm{b}^{*}}$ & $295.1 \pm 2.9^{\mathrm{b}^{*}}$ & $198.0 \pm 1.8^{\mathrm{bcd}}$ \\
& III & $448.1 \pm 1.5^{\mathrm{b}^{*}}$ & $182.5 \pm 2.5^{\mathrm{a}^{*}}$ & $214.2 \pm 0.8^{\mathrm{c}^{*}}$ \\
& IV & $439 \pm 41^{\mathrm{ab}}$ & $175.3 \pm 1.4^{\mathrm{a}^{*}}$ & $227.3 \pm 0.5^{\mathrm{d}^{*}}$ \\
JTB & I & $538.6 \pm 1.2^{\mathrm{a}}$ & $178 \pm 13^{\mathrm{b}}$ & $90.9 \pm 1.1^{\mathrm{b}^{*}}$ \\
& II & $954.8 \pm 0.4^{\mathrm{b}^{*}}$ & $393.8 \pm 0.2^{\mathrm{a}^{*}}$ & $72.90 \pm 0.11^{\mathrm{a}^{*}}$ \\
& III & $612 \pm 14^{\mathrm{a}^{*}}$ & $231.4 \pm 2.2^{\mathrm{b}^{*}}$ & $79.68 \pm 0.30^{\mathrm{b}^{*}}$ \\
& IV & $500 \pm 19^{\mathrm{a}}$ & $166 \pm 14^{\mathrm{ab}}$ & $84.6 \pm 1.4^{\mathrm{a}^{*}}$ \\
Salmon & I & $433 \pm 14^{\mathrm{a}^{*}}$ & $525.4 \pm 1.4^{\mathrm{a}^{*}}$ & $507.6 \pm 0.6^{\mathrm{a}^{*}}$ \\
& II & $569 \pm 15^{\mathrm{b}^{*}}$ & $711 \pm 38^{\mathrm{abc}}$ & $320.2 \pm 9.4^{\mathrm{b}^{*}}$ \\
& III & $368 \pm 45^{\mathrm{a}^{*}}$ & $501.4 \pm 2.2^{\mathrm{b}^{*}}$ & $409.5 \pm 9.99^{\mathrm{c}^{*}}$ \\
& IV & $425.6 \pm 0.7^{\mathrm{ab}}$ & $511.8 \pm 0.7^{\mathrm{c}^{*}}$ & $511.4 \pm 5.5^{\mathrm{a}^{*}}$ \\
\hline
\end{tabular}

Data are expressed as mean \pm SD (mg/100 g FW) of triplicate analyses. Different superscript lowercase letters $(\mathrm{a}-\mathrm{c})$ in the same column indicate significant difference at $p<0.05$ (Games-Howell post-hoc test). Asterisk $\left(^{*}\right)$ indicates significant difference between raw and different cooking methods for same fish sample at $p<0.05$ (paired sample $t$-test).

$\dagger$ Method: I = Steaming, II = Deep frying, III = Grilling, IV = Baking in foil. 
Table 5 Quantitative determination of DHA and EPA content in fish fillets of selected fish prepared using different cooking methods.

\begin{tabular}{llccc}
\hline Sample & Meth. $^{\dagger}$ & DHA & EPA & DHA + EPA \\
\hline YS & I & $49.55 \pm 0.25^{\mathrm{a}}$ & $62.81 \pm 0.06^{\mathrm{a}}$ & $112.4 \pm 0.1^{\mathrm{a}^{*}}$ \\
& II & $41.5 \pm 2.9^{\mathrm{a}^{*}}$ & $51.72 \pm 0.31^{\mathrm{b}^{*}}$ & $93.2 \pm 1.8^{\mathrm{b}^{*}}$ \\
& III & $44.5 \pm 2.5^{\mathrm{a}^{*}}$ & $54.8 \pm 1.4^{\mathrm{a}^{* *}}$ & $99.24 \pm 0.75^{\mathrm{c}^{*}}$ \\
& IV & $48.5 \pm 1.4^{\mathrm{a}}$ & $59.0 \pm 2.1^{\mathrm{ab}}$ & $107.5 \pm 0.5^{\mathrm{d}^{*}}$ \\
JTB & I & $12.24 \pm 0.49^{\mathrm{a}}$ & $11.21 \pm 0.34^{\mathrm{ab}}$ & $23.45 \pm 0.10^{\mathrm{a}^{*}}$ \\
& II & $9.58 \pm 0.01^{\mathrm{a}^{*}}$ & $8.27 \pm 0.16^{\mathrm{a}^{*}}$ & $17.84 \pm 0.11^{\mathrm{b}^{*}}$ \\
& III & $11.25 \pm 0.10^{\mathrm{a}^{*}}$ & $9.17 \pm 0.71^{\mathrm{ab}}$ & $20.42 \pm 0.43^{\mathrm{a}^{*}}$ \\
& IV & $11.94 \pm 0.52^{\mathrm{a}}$ & $10.87 \pm 0.16^{\mathrm{b}}$ & $22.81 \pm 0.48^{\mathrm{ac}}$ \\
Salmon & I & $10.42 \pm 0.11^{\mathrm{a}}$ & $42.20 \pm 0.10^{\mathrm{a}}$ & $52.61 \pm 0.15^{\mathrm{a}^{*}}$ \\
& II & $7.22 \pm 0.01^{\mathrm{b}^{*}}$ & $23.10 \pm 0.88^{\mathrm{b}^{*}}$ & $30.32 \pm 0.63^{\mathrm{b}^{*}}$ \\
& III & $6.89 \pm 0.62^{\mathrm{bc}^{* *}}$ & $30.0 \pm 1.6^{\mathrm{c}^{*}}$ & $36.9 \pm 1.7^{\mathrm{c}^{*}}$ \\
& IV & $9.78 \pm 0.04^{\mathrm{a}}$ & $41.11 \pm 0.33^{\mathrm{a}}$ & $50.89 \pm 0.26^{\mathrm{d}^{*}}$ \\
\end{tabular}

Data are expressed as mean \pm SD $(\mathrm{mg} / 100 \mathrm{~g} \mathrm{FW})$ of triplicate analyses. Different superscript lowercase letters $(\mathrm{a}-\mathrm{c})$ in the same column indicate significant difference at $p<0.05$ (Games-Howell post-hoc test). Asterisk $(*)$ indicates significant difference between raw and different cooking methods for same fish sample at $p<0.05$ (paired sample $t$-test).

$\dagger$ Method: I = Steaming, II = Deep frying, III = Grilling, IV = Baking in foil.

No significant difference was found for DHA content in both fillets of yellowstripe scad and Japanese threadfin bream between different cooking methods (Table 5). DHA content in fried and grilled salmon fillets was significantly lower $(p<$ 0.05) than the content in fish fillets prepared by steaming and baking in foil. Comparing the results obtained for different cooking methods, one-way ANOVA (Games-Howell post-hoc test) revealed that the frying method retained a significantly lower $(\mathrm{p}<$ 0.05) EPA content in yellowstripe scad fillet than the steaming method. As shown in Table 5, EPA content in fried fillet of Japanese threadfin bream was significantly lower $(p<0.05)$ than the content in the fish fillet prepared with baking in foil method. Both grilling and frying methods showed a significantly lower $(p<0.05)$ EPA content in salmon fillet than steaming and baking in foil methods. Frying of salmon fillet also caused a significant increase in degradation $(p<0.05)$ of EPA compared to grilling method.

As shown in Table 5, retention of DHA and EPA in all fish fillets was reduced after cooking with these cooking protocols. Paired sample $t$-test analysis proved that there was a significant decrease $(p<$ 0.05) in retention of DHA and EPA in all fish fillets after cooked using frying and grilling methods com- pared to the raw fillets. No significant difference in the retention of DHA and EPA was found for all steamed and baked fish fillets before and after cooking except for retention of DHA in fried salmon fillet. Results obtained from this study also show that the frying method resulted in the lowest retention of DHA and EPA in all the studied fish fillets. Also, grilled salmon fillet had a lower retention of DHA than fried salmon fillet. Furthermore, no significant difference was found for the retention of DHA and EPA between steaming and baking in foil for all the fish fillets.

For retention of EPA + DHA in the fish fillets, fried fish fillets retained the lowest content, followed by grilling, baking in foil, and steaming for all fish fillets. In fact, yellowstripe scad had the highest DHA + EPA content among the fish fillets studied after being subjected to different cooking methods (steaming, frying, grilling, and baking in foil). Furthermore, retention of DHA + EPA for all the cooked fish fillets was significantly lower than the raw fish samples.

The decrease of DHA and EPA content in fried fish fillets was supported by a previous research. In Ref. 32, it was reported that both cod and salmon fillets experience a reduction in DHA and EPA content after pan-fried using olive and sunflower oils. A similar finding is also observed for sardine and mackerel which reported by a previous study ${ }^{6}$. A modest reduction of DHA and EPA content in fried humpback salmon fillet was reported previously compared with boiling and roasting methods ${ }^{5}$.

In this study, the decrease in DHA and EPA content of grilled fish fillets is in agreement with a previous study that grilled marine fish products which are rich in EPA experienced a moderate decrease in PUFA level ${ }^{33}$. In contrast, steaming and baking methods showed no significant decrease of DHA and EPA content in the fish fillets. A previous study reported that baking and steaming have little influence on fatty acid composition in the fish species ${ }^{18}$. It was also hypothesized that baking could be a cooking technique that involves a mild heating rate with moderate cooking yield ${ }^{9}$. In addition, DHA and EPA content in steamed and oven-baked fish were significantly higher $(p<0.05)$ than deep-fried fish ${ }^{34}$.

Thermal treatment has been reported for its increasing susceptibility of omega-3 PUFA towards oxidation $^{35}$. Nutritional changes in food depend on the mode of cooking and specifically the applied temperature ${ }^{3}$. In this study, the temperature of frying, grilling, and baking in foil was set at 
$180^{\circ} \mathrm{C}$. Both frying and grilling methods exposed the fish fillets directly to heat. Exposure to hightemperature could reduce DHA and EPA content in the fried and grilled fish fillets. However, the steaming and baking in foil methods showed no significant decrease in DHA and EPA content of all fish samples. It could be explained by the lower temperature used for steaming of fish and the fish fillets were steam-cooked by hot steam. Baking in foil also shared a similar mode of cooking as for steaming, where the fish fillets were wrapped with aluminium foil for preventing direct heat contact. Thus the internal temperature of the fillet in baking foil does not exceed $75^{\circ} \mathrm{C}$.

In addition to temperature, surface contact, fish size and initial fat content of the fish samples could also affect fatty acid composition of fish fillet during cooking ${ }^{36}$. A study showed that the best lipid stability was obtained at a minimum cooking time of $38 \mathrm{~min}$ compared to $54 \mathrm{~min}$ and a lower temperature of $55^{\circ} \mathrm{C}$ compared to $100^{\circ} \mathrm{C}^{37}$. Thus the variation of DHA and EPA contents in the fish samples applying different cooking methods could be due to the inconsistent surface area of fish fillets, as well as inappropriate cooking duration adopted in this study. It was also suggested that the temperature set for heating any food should be adaptable to the food size, for example, the larger the surface of food, the lower the temperature ${ }^{15}$. Although it was also hypothesized that there are high levels of natural antioxidants in fish species of Salmonidae family with red coloured flesh which can prevent oxidation of PUFAs during heat treatments ${ }^{5}$. However, in this study, the fried and grilled salmon fillets had significantly lower retention of DHA and EPA than the steamed and baked fillets.

\section{True retention value of DHA and EPA using different cooking methods}

Fig. 2 demonstrates true retention values (TRVs) of DHA and EPA in fish fillets prepared using different cooking methods. Statistical analysis applying oneway ANOVA (Games-Holl post-hoc test) shows that TRVs of DHA and EPA for both steaming and baking in foil were significantly higher $(p<0.05)$ than TRVs of DHA and EPA for frying and grilling in all fish samples. No significant difference in TRVs of DHA or EPA was found between steaming and baking in foil, as well as between frying and grilling in all the fish fillets.

Comparing among the fish fillets, TRVs of DHA and EPA in salmon fillet for steaming and baking in foil methods were not significantly lower than the

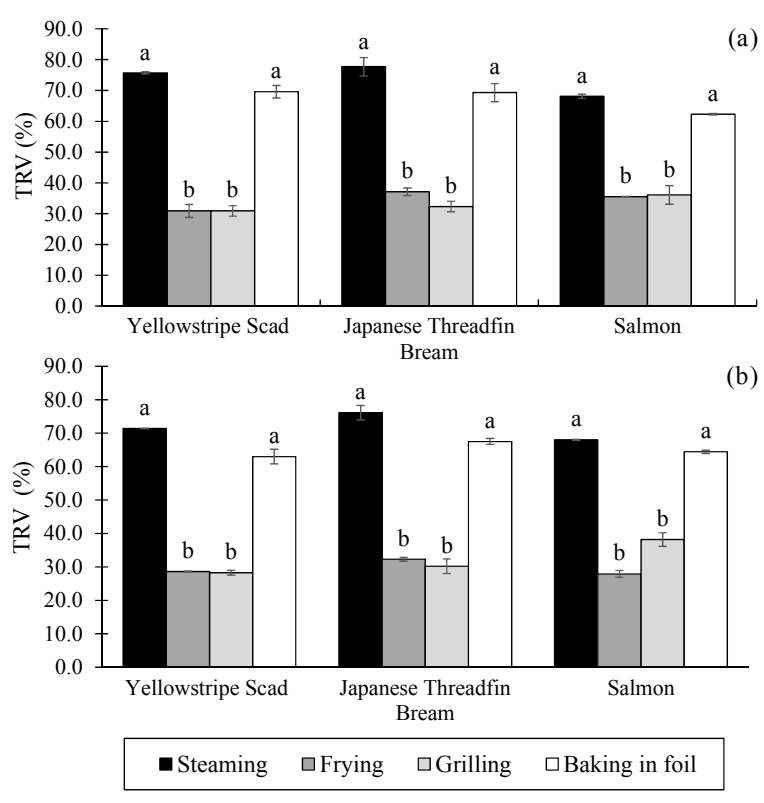

Fig. 2 True retention value (TRV) of (a) DHA and (b) EPA in fish fillets applying different cooking methods. Data are expressed as mean \pm SD (\%) of triplicate analyses. Bars with different lowercase letters (a-b) indicate significant difference between different cooking methods for same fish sample at $p<0.05$ (Games-Howell post-hoc test).

other two fish fillets except for the baked fillet of yellowstripe scad (Fig. 2). In fact, yellowstripe scad and Japanese threadfin bream are classified as lowfat fish ( $2 \%$ and $1 \%$, respectively) while salmon is a fatty fish (10\%). The low TRV in salmon fillet can be explained by the fact that low-fat fish such as catfish ( $2 \%$ fat) is much less susceptible to fat drip during heat treatment than high-fat fish such as salmon ${ }^{38}$.

Limited studies have been done on TRVs of fatty acids in fish fillets treated with different cooking methods. In this study, retention of DHA and EPA in all steamed fish fillets was within the proposed range of $71-85 \%{ }^{39}$. The trend of TRVs of DHA and EPA in the studied fish fillets was also in agreement with the previous study ${ }^{9}$, where baking in aluminium foil method showed the highest TRVs of DHA and EPA in European sea bass while oven and microwave heating had the lowest TRVs of DHA and EPA. However, more studies are needed for further investigation of these cooking methods on retention of DHA and EPA in other pelagic and demersal fish.

\section{Association between cooking methods and TRV} of EPA and DHA

Association between different cooking methods and the TRVs of DHA and EPA was determined using 
a chi-squared test. Results show that there was a statistically significant association between cooking methods and TRVs of DHA and EPA at $p<0.01$. Steaming and baking in foil (moist-heat cooking method) were associated with high TRVs of DHA and EPA, whereas frying and grilling (dry-heat cooking method) were associated with low TRVs for DHA and EPA. Hence we conclude that steaming and baking in foil methods are associated with higher retention of DHA and EPA than frying and grilling methods in both local fish and salmon since these moist-heat cooking methods give high TRVs.

Determination of total fatty acids, DHA, and EPA content in different fish species prepared with different cooking methods has been widely done. However, none of those studies has determined association between different cooking methods and retention of DHA and EPA in fish fillets. Hence the data of this study can serve as a reference and preliminary finding for future study in further exploitation of fatty acid composition by using different cooking methods especially in these less popular sources of EPA and DHA.

\section{CONCLUSIONS}

This study concluded that steaming and baking in foil methods have little effect on reduction of DHA and EPA content in the studied fish samples, as well as total fatty acids content, whereas frying and grilling have a considerably high reduction of DHA and EPA content in the cooked fillets compared to raw fillets. Frying method also tends to have a lower retention of DHA and EPA in all fish fillets compared with the other cooking methods. Steaming and baking in foil are the best cooking methods for retaining DHA and EPA in fish fillet while both frying and grilling are the high-temperature cooking. Moist-heat cooking methods (steaming and baking in foil) are also associated with higher retention of DHA and EPA in both local fish and salmon which showed higher TRVs in comparison to dry-heat cooking methods (frying and grilling). Yellowstripe scad remains as a good source of total PUFA even after using different cooking methods, which also had the highest DHA and EPA among the fish samples tested. It is also considered as the best low-fat fish caught from the Strait of Malacca. Consumption of steamed fillet of yellowstripe scad is able to maintain good health through increased intake of DHA and EPA.

Acknowledgements: We thank the laboratory staff of the Department of Nutrition and Dietetics for helping with the analysis of fatty acids.

\section{REFERENCES}

1. Institute for Public Health (2014) National health and morbidity survey 2014: Malaysian adult survey, Vol II: Survey Findings, Ministry of Health Malaysia, Kuala Lumpur.

2. Hsieh RJ, Kinsella JE (1989) Oxidation of polyunsaturated fatty acids: mechanisms, products, and inhibition with emphasis on fish. Adv Food Nutr Res 33, 233-341.

3. Koubaa A, Mihoubi NB, Abdelmouleh A, Bouain A (2012) Comparison of the effects of four cooking methods on fatty acid profiles and nutritional composition of red mullet (Mullus barbatus) muscle. Food Sci Biotechnol 21, 1243-50.

4. Rosnes JT, Skåra T, Skipnes D (2011) Recent advances in minimal heat processing of fish: effects on microbiological activity and safety. Food Bioproc Tech 4, 833-48.

5. Gladyshev MI, Sushchik NN, Gubanenko GA, Demirchieva SM, Kalachova GS (2006) Effect of way of cooking on content of essential polyunsaturated fatty acids in muscle tissue of humpback salmon (Oncorhynchus gorbuscha). Food Chem 96, 446-51.

6. Candela M, Astiasaran I, Bello J (1998) Deep-fat frying modifies high-fat fish lipid fraction. J Agr Food Chem 46, 2793-6.

7. Abd Aziz N, Azlan A, Ismail A, Mohd Alinafiah S, Razman MR (2013) Quantitative determination of fatty acids in marine fish and shellfish from warm water of Straits of Malacca for nutraceutical purposes. BioMed Res Int 2013, 284329.

8. Kris-Etherton PM, Harris WS, Appel LJ (2003) Omega-3 fatty acids and cardiovascular disease new recommendations from the American Heart Association. Arterioscler Thromb Vasc Biol 23, 151-2.

9. Badiani A, Stipa S, Bitossi F, Pirini M, Bonaldo A, Gatta PP, Rotolo M, Testi S (2013) True retention of nutrients upon household cooking of farmed portionsize European sea bass (Dicentrarchus labrax L.). LWT Food Sci Tech 50, 72-7.

10. Bligh EG, Dyer WJ (1959) A rapid method of total lipid extraction and purification. Can J Biochem Physiol 37, 911-7.

11. Joseph JD, Ackman RG (1992) Capillary column gas chromatography method for analysis of encapsulated fish oil and fish oil ethyl esters: collaborative study. $J$ AOAC Int 75, 488-506.

12. Visentainer JV, Claus T, Santos Jr OO, Chiavelli LUR, Maruyama SA (2014) Analytical aspects of the flame ionization detection in comparison with mass spectrometry with emphasis on fatty acids and their esters. In: Guo X (ed) Advances in Gas Chromatography, IntechOpen, London, pp 39-56.

13. Murphy EW, Criner PE, Gray BC (1975) Comparisons 
of methods for calculating retentions of nutrients in cooked foods. J Agr Food Chem 23, 1153-7.

14. Nurnadia AA, Azrina A, Amin I (2011) Proximate composition and energetic value of selected marine fish and shellfish from the west coast of Peninsular Malaysia. Int Food Res $J$ 18, 137-48.

15. Bognár A (1998) Comparative study of frying to other cooking techniques influence on the nutritive value. Grasas Aceites 49, 250-60.

16. Costa S, Afonso C, Cardoso C, Batista I, Chaveiro N, Nunes ML, Bandarra NM (2015) Fatty acids, mercury, and methylmercury bioaccessibility in salmon (Salmo salar) using an in vitro model: effect of culinary treatment. Food Chem 185, 268-76.

17. Ladikos D, Lougovois V (1990) Lipid oxidation in muscle foods: a review. Food Chem 35, 295-314.

18. Suzuki T (1981) Fish and Krill Protein: Processing Technology, Springer, Netherlands.

19. Honikel KO (2004) Water-holding capacity of meat. In: te Pas MF, Everts ME, Haagsman HP (eds) Muscle Development of Livestock Animals: Physiology, Genetics and Meat Quality, CABI Publishing, Cambridge, pp 389-400.

20. Addis PB (1986) Occurrence of lipid oxidation products in foods. Food Chem Toxicol 24, 1021-30.

21. Tang S, Kerry JP, Sheehan D, Buckley DJ, Morrissey PA (2001) Antioxidative effect of added tea catechins on susceptibility of cooked red meat, poultry and fish patties to lipid oxidation. Food Res Int 34, 651-7.

22. Gall KL, Otwell WS, Koburger JA, Appledorf $\mathrm{H}$ (1983) Effects of four cooking methods on proximate, mineral and fatty acid composition of fish fillets. J Food Sci 48, 1068-74.

23. Castro-González I, Maafs-Rodríguez AG, Pérez-Gil Romo F (2015) Effect of six different cooking techniques in the nutritional composition of two fish species previously selected as optimal for renal patient's diet. J Food Sci Tech 52, 4196-205.

24. Pirini M, Testi S, Ventrella V, Pagliarani A, Badiani A (2010) Blue-back fish: fatty acid profile in selected seasons and retention upon baking. Food Chem 123, 306-14.

25. Kong F, Tang J, Rasco B, Crapo C, Smiley S (2007) Quality changes of salmon (Oncorhynchus gorbuscha) muscle during thermal processing. J Food Sci 72, S103-11.

26. Lin SW (2012) Palm oil. In: Gunstone FD (ed) Vegetable Oils in Food Technology: Composition, Properties and Uses, 2nd edn, Blackwell Publishing, UK, pp 25-58.

27. Rabu A, Azlan A, Khoo HE (2017) Heat stability of fatty acids of selected blended palm oils during potato frying. Carpath J Food Sci Tech 9(1), 80-9.

28. Tenyang N, Womeni HM, Linder M, Tiencheu B, Villeneuve P, Tchouanguep Mbiapo F (2014) The chemical composition, fatty acid, amino acid profiles and mineral content of six fish species commercialized on the Wouri river coast in Cameroon. Riv Ital Sostanze Grasse 91, 129-38.

29. Minarny G, Purnomo H, Rosyidi D (2014) Fatty acid profile of fish from Central Sulawesi, Indonesia. Int Food Res $J$ 21, 979-83.

30. Henderson RJ, Tocher DR (1987) The lipid composition and biochemistry of freshwater fish. Progr Lipid Res 26, 281-347.

31. de Castro FAF, Sant'Ana HMP, Campos FM, Costa NMB, Silva MTC, Salaro AL, Franceschini SDCC (2007) Fatty acid composition of three freshwater fishes under different storage and cooking processes. Food Chem 103, 1080-90.

32. Ansorena D, Guembe A, Mendizábal T, Astiasarán I (2010) Effect of fish and oil nature on frying process and nutritional product quality. J Food Sci 75, H62-7.

33. Shozen KI, Ohshima T, Ushio H, Koizumi C (1995) Formation of cholesterol oxides in marine fish products induced by grilling. Fish Sci 61, 817-21.

34. Larsen D, Quek SY, Eyres L (2010) Effect of cooking method on the fatty acid profile of New Zealand King Salmon (Oncorhynchus tshawytscha). Food Chem 119, 785-90.

35. Regulska-Ilow B, Ilow R (2002) Comparison of the effects of microwaving cooking and conventional cooking methods on the composition of fatty acids and fat quality indicators in herring. Food Nahrung 46, 383-8.

36. Marichamy G, Raja P, Veerasingam S, Rajagopal S, Venkatachalapathy R (2009) Fatty acid composition of Indian mackerel (Rastrelliger kanagurta) under different cooking methods. Curr Res J Biol Sci 1, 109-12.

37. Undeland I, Ekstrand B, Lingnert H (1998) Lipid oxidation in minced herring (Clupea harengus) during frozen storage. Effect of washing and precooking. J Agr Food Chem 46, 2319-28.

38. Domiszewski Z, Bienkiewicz G, Plust D (2011) Effects of different heat treatments on lipid quality of striped catfish (Pangasius hypophthalmus). Acta Sci Pol Tech Aliment 10, 359-73.

39. Bognár A (2002) Tables on Weight Yield of Food and Retention Factors of Food Constituents for the Calculation of Nutrient Composition of Cooked Foods (Dishes), Berichte der Bundesforschungsanstalt für Ernährung Vol 02-03, Karlsruhe, Germany, pp 1-10. 